\title{
Effect of back reflectors on photon absorption in thin-film amorphous silicon solar cells
}

\author{
Mohammad I. Hossain ${ }^{1,2}$ (ID $\cdot$ Wayesh Qarony ${ }^{1,2}$ • \\ M. Khalid Hossain ${ }^{3}$ (D) M. K. Debnath ${ }^{2}$ - M. Jalal Uddin ${ }^{4}$. \\ Yuen Hong Tsang ${ }^{1}$
}

Received: 7 July 2017 / Accepted: 12 August 2017/Published online: 30 August 2017

(c) The Author(s) 2017. This article is an open access publication

\begin{abstract}
In thin-film solar cells, the photocurrent conversion productivity can be distinctly boosted-up utilizing a proper back reflector. Herein, the impact of different smooth and textured back reflectors was explored and effectuated to study the optical phenomena with interface engineering strategies and characteristics of transparent contacts. A unique type of wet-chemically textured glasssubstrate 3D etching mask used in superstrate $(\mathrm{p}-\mathrm{i}-\mathrm{n})$ amorphous silicon-based solar cell along with legitimated back reflector permits joining the standard light-trapping methodologies, which are utilized to upgrade the energy conversion efficiency (ECE). To investigate the optical and electrical properties of solar cell structure, the optical simulations in three-dimensional measurements (3D) were performed utilizing finite-difference time-domain (FDTD) technique. This design methodology allows to determine the power losses, quantum efficiencies, and short-circuit
\end{abstract}

Mohammad I. Hossain and Wayesh Qarony are contributed equally to this work.

Yuen Hong Tsang

yuen.tsang@polyu.edu.hk

M. Khalid Hossain

khalid.baec@yahoo.com

1 Department of Applied Physics, The Hong Kong Polytechnic University, Hung Hom, Hong Kong

2 Electrical and Electronic Engineering, American International University-Bangladesh (AIUB), Dhaka 1213, Bangladesh

3 Institute of Electronics, Atomic Energy Research Establishment, Bangladesh Atomic Energy Commission, Savar, PO. Box. No. 3787, Dhaka 1349, Bangladesh

4 Department of Radio Sciences and Engineering, Kwangwoon University, Seoul 01897, Republic of Korea current densities of various layers in such solar cell. The short-circuit current densities for different reflectors were varied from 11.50 to 13.27 and 13.81 to $16.36 \mathrm{~mA} / \mathrm{cm}^{2}$ for the smooth and pyramidal textured solar cells, individually. Contrasted with the comparable flat reference cell, the short-circuit current density of textured solar cell was increased by around $24 \%$, and most extreme outer quantum efficiencies rose from 79 to $86.5 \%$. The photon absorption was fundamentally improved in the spectral region from 600 to $800 \mathrm{~nm}$ with no decrease of photocurrent shorter than $600-\mathrm{nm}$ wavelength. Therefore, these optimized designs will help to build the effective plans next-generation amorphous silicon-based solar cells.

Keywords a-Si:H · Superstrate $\cdot 3 D$ FDTD $\cdot$ Photon absorption · Power loss

\section{Introduction}

Silicon-based devices predominantly rule the current photovoltaic markets because of their present perfect and cheap manufacture technique and earth wealth (Green 2006; Hsu et al. 2011; Dubey et al. 2014). Hydrogenated amorphous silicon (a-Si:H) is a favorite candidate for executing cutting edge thin-film solar cell. In any case, it has a weak absorption of longer wavelength range due to their backhanded material properties, which likewise restrains the general power conversion efficiency (Zeman et al. 2000; Muller et al. 2001; Green 2006; Hsu et al. 2011; Kim et al. 2011; Dubey et al. 2014; Barugkin et al. 2016). In thin-film solar cell utilizing hydrogenated amorphous silicon, the active layer cannot be made thick because of their incited light degradation issue, so it must be thinner (as a rule $<320 \mathrm{~nm}$ ) (Jovanov et al. 2013a, b; Palanchoke 
et al. 2013). As an outcome, light trapping or photon management ideas and knowledgeable back contacts are essential for actualizing a useful thin-film amorphous silicon solar cell (Hsu et al. 2011; Dubey et al. 2014; Barugkin et al. 2016). As of late, different light-trapping systems have been severely contemplated where texturing at the surface of the solar cell assumes an explicit part in dispersing and diffracting the incident light through the solar cell structure (Springer et al. 2004; Ferry et al. 2009, 2010; Escarre et al. 2011; Jovanov et al. 2017). Texturing at the front and back interfaces permits to build light diffusing, optical path length without expanding optical losses, the productive coupling of light, and total reflection of the solar cell (Zeman et al. 2000; Muller et al. 2001; Jovanov et al. 2013b). The optical path length of a material with a refractive record of $n$ is enhanced by a component $4 n^{2}$ which has a huge impact making a high-efficiency solar cell (Ferry et al. 2010; Escarre et al. 2011). As a rule, the nanotextured surface is utilized to satisfy such prerequisites for making productive solar cells (Kim et al. 2011; Palanchoke et al. 2012; Jovanov et al. 2013a; Wang et al. 2017). Moreover, it is conceivable to accomplish higher charge transporter era in the optically thin absorber if reflectivity in the back contact is enhanced (Palanchoke et al. 2013; Chen et al. 2016). The aluminum-doped zinc oxide ( $\mathrm{ZnO}: \mathrm{Al}$ ) coordinated with metal has earned a ton of consideration regarding expanding the impression of light from the back contact and unabsorbed reflected light once more into the solar cell which additionally builds the light trapping (Springer et al. 2004; Catchpole and Polman 2008; Jovanov et al. 2017). In addition, to gain more photon absorption and higher short-circuit current density, the parasitic losses at the front and back contacts must be diminished for sufficient solar cell improvement (Muller et al. 2004; Catchpole and Polman 2008; Palanchoke et al. 2013).

In this paper, the electrical and optical exhibitions of generally utilized back reflectors (air, Ag, Al, and PEC) covered with $\mathrm{ZnO}: \mathrm{Al}$ was contrasted and shown the qualities of the solar cell. Our ultimate target was to research the effect of different back reflectors investigating the optical phenomena at the back contact, where various interface engineering strategies were applied to observe the impact on photon absorption for the flat and textured substrates. Moreover, a special type of textured glass substrate fabricated by ion beam etching using a wet-chemically textured $3 \mathrm{D}$ etching mask was employed along with several back reflectors for further studying light trapping and photon absorption enhancement within the unit cell structure. The optical simulations permitted deciding the implications of smooth and textured back reflectors on such light-trapping scheme for making productive solar cells. The schematic diagrams of a thin-film flat and textured amorphous silicon

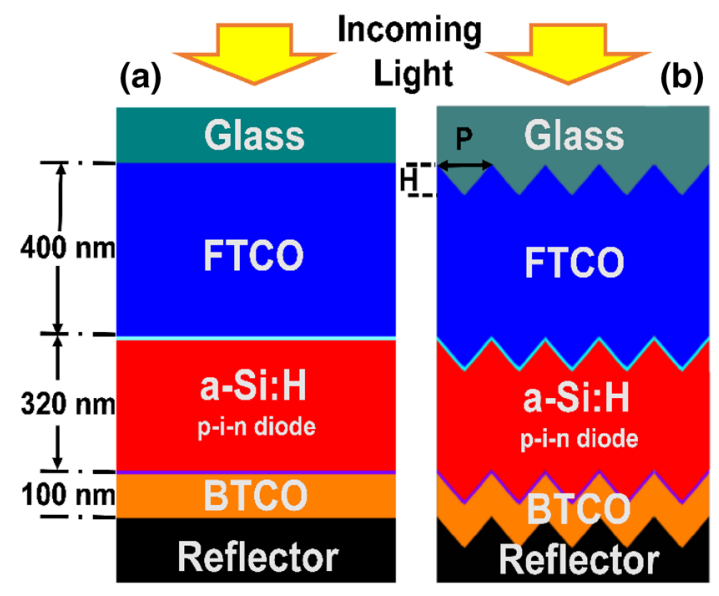

Fig. 1 Schematic outline of a smooth and $\mathbf{b}$ pyramidal textured thinfilm amorphous silicon solar cell

solar cells are shown in Fig. 1a, b, separately. The light trapping or photon management and losses at single layers were examined by FDTD optical simulations (Muller et al. 2004; Tamang et al. 2016a; Jovanov et al. 2017). The developed 3D optical model is used to model the solar cells and permit to select an efficient back reflector achieving higher current density.

The outlined device and optical model for the simulation of the superstrate $(\mathrm{p}-\mathrm{i}-\mathrm{n})$ configured amorphous silicon thinfilm solar cells are clarified in "Design and optical model". Simulation results for the designed solar cell are explained about in "Simulation results". Moreover, the impact of the back contact is explored in "Simulation results", trailed by a rundown of the outcomes in "Conclusion".

\section{Design and optical model}

An optical model was designed for the solar cell simulation, which allows deciding losses at the individual layers. In this examination, hydrogenated amorphous silicon solar cells in superstrate setup were created to research the optical phenomena of solar cell structure, where the schematic cross-sectional area of the solar cell on a flat substrate is shown in Fig. 3a.

In our planned solar cell structure, a thick glass substrate covered with 400-nm-thick fluorine-doped tin oxide $\left(\mathrm{SnO}_{2}: \mathrm{F}\right)$ was utilized as a front contact (Muller et al. 2004). The amorphous silicon diode was contained a 10-nm p-doped layer, 300-nm intrinsic layer, and 10-nm $\mathrm{n}$-doped layer, which was in arrangement association with first transparent contact layer. In like manner, we considered a thick metal reflector covered with 100-nm ZnO:Al transparent oxide layer, which permits to improve reflection from the back. From now on, four various contact arrangements (ZnO:Al/air, $\mathrm{ZnO}: \mathrm{Al} / \mathrm{Ag}, \mathrm{ZnO}: \mathrm{Al} / \mathrm{Al}$, and 
$\mathrm{ZnO}: \mathrm{Al} / \mathrm{PEC}$ ) were inspected for the simulation study. The material properties ( $n$ and $k$ values) for the distinct layers in solar cell structure were taken from the reported literature (Zeman et al. 2000; Green 2006; Konagai 2011; Dewan et al. 2011; Tamang et al. 2016b). At that point, the real complex interface morphologies were considered for the textured solar cell simulation (Sai and Kondo 2009b; Dewan et al. 2012, 2015b). A periodic surface for a unit cell can rough the arbitrarily textured substrate for the optical examination (Haug et al. 2009; Sai and Kondo 2009a; Dewan et al. 2011). Figure 2a, b demonstrates the scanning electron microscope (SEM) images of $\mathrm{SnO}_{2}: \mathrm{F}$ substrate (Muller et al. 2004) and comparative simulated interface surface morphology for the displaying. It is approximated that the surface of nanotextured $\mathrm{SnO}_{2}: \mathrm{F}$ resembles the organization of pyramids, which has a particular measurement (period and height). The pyramid has a regular span of $260 \mathrm{~nm}$ and height of $75 \mathrm{~nm}$. Likewise, we considered a pyramid which has a consistent opening edge of $120^{\circ}$. All through the examination, FDTD strategy in three dimensions (3D) was utilized to mimic the solar cell investigating the optical wave spread and compute the losses in the individual layers (Palanchoke et al. 2012; Huang et al. 2013; Tamang et al. 2016c).

The time average power loss profiles have been processed from the simulated electric field appropriation. The incident light has an electric field amplitude of $1 \mathrm{~V} / \mathrm{m}$ (Dewan et al. 2011; Palanchoke et al. 2013; Tamang et al. 2016a). From that point forward, the quantum efficiency (QE) was resolved to see multiple occurrence photons absorbed in the intrinsic layer. Since we were not concerned about electrical losses, it was assumed that $100 \%$ photons were absorbed into the solar cell conveying the most astounding point of confinement of internal quantum efficiency (Dewan and Knipp 2009; Trapping et al. 2011; Dewan et al. 2011). The approximation is valid, since a 300-nm-thick, intrinsic amorphous silicon was utilized, which has an excellent charge extraction and no light degradation issue. Moreover, the short-circuit current density was figured out from the QE and spectral irradiance. The counts are performed in detail in the announced writing (Müller et al. 2001; Paetzold et al. 2011; Tamang et al. 2016a).

\section{Simulation results}

The solar cells with flat and pyramidal textured substrates were examined all through the simulation to observe the impact of rear reflectors on photon absorptions. The different back reflectors (air, Al, Ag, and PEC) were studied and contrasted with each other on their simulated power loss profiles, quantum efficiencies, and short-circuit currents. In the first step, the optics of a flat a-Si:H solar cell was investigated, where both front and back contacts were smooth. In the second stage, the pyramidal textured substrate was considered to accomplish the efficient light incoupling in the front and improve the diffusing/diffraction and total inner reflection (Dewan et al. 2015a). In FDTD simulations, Maxwell's curl conditions were precisely calculated to understand the losses at the individual layers for the wavelength extending from 300 to $800 \mathrm{~nm}$ (Haug et al. 2009; Dewan et al. 2011, 2015a).

\section{Solar cell with smooth substrate}

The time standard power loss can be figured utilizing the following equation (Palanchoke et al. 2012):

$Q(x, y, z)=\frac{1}{2} c \varepsilon_{0} n \alpha|E(x, y, z)|^{2}$,

where $\alpha$ is the absorption coefficient, which relates the extinction coefficient $(k=\alpha \lambda / 4 \pi)$, and $n$ is the real part of the complex refractive index. $E$ is the electric field.

The power loss profiles of a hydrogenated amorphous silicon solar cell on a flat substrate are shown in Fig. 3b, c for wavelengths of 400 and $600 \mathrm{~nm}$, individually. The power loss profiles were exhibited while silver back reflector was utilized. The power loss in the amorphous silicon layer is overwhelmed by the productive and ruinous
Fig. 2 a Scanning electron microscope images of $\mathrm{SnO}_{2}: \mathrm{F}$ substrate on the glass. Reprinted with permission from (Muller et al. 2004) and b corresponding simulated interface texture morphology

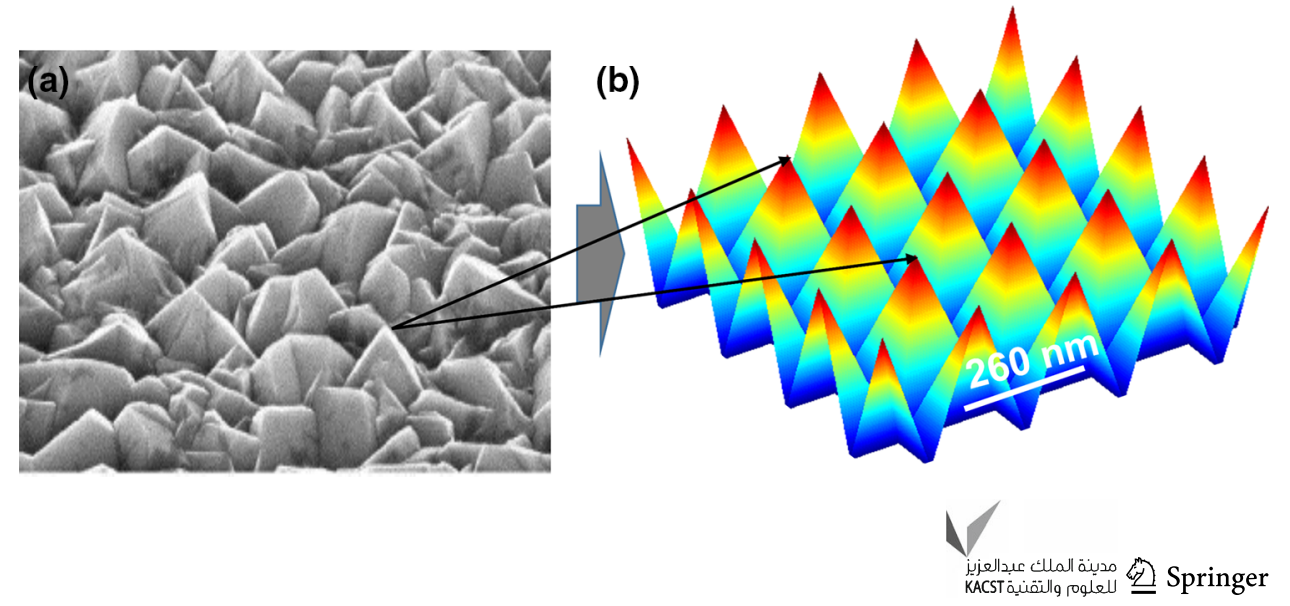


Fig. 3 a Schematic of a unit cell with smooth silver reflector and corresponding simulated power loss profile for b 400 and c $600-\mathrm{nm}$ wavelengths under the standard light

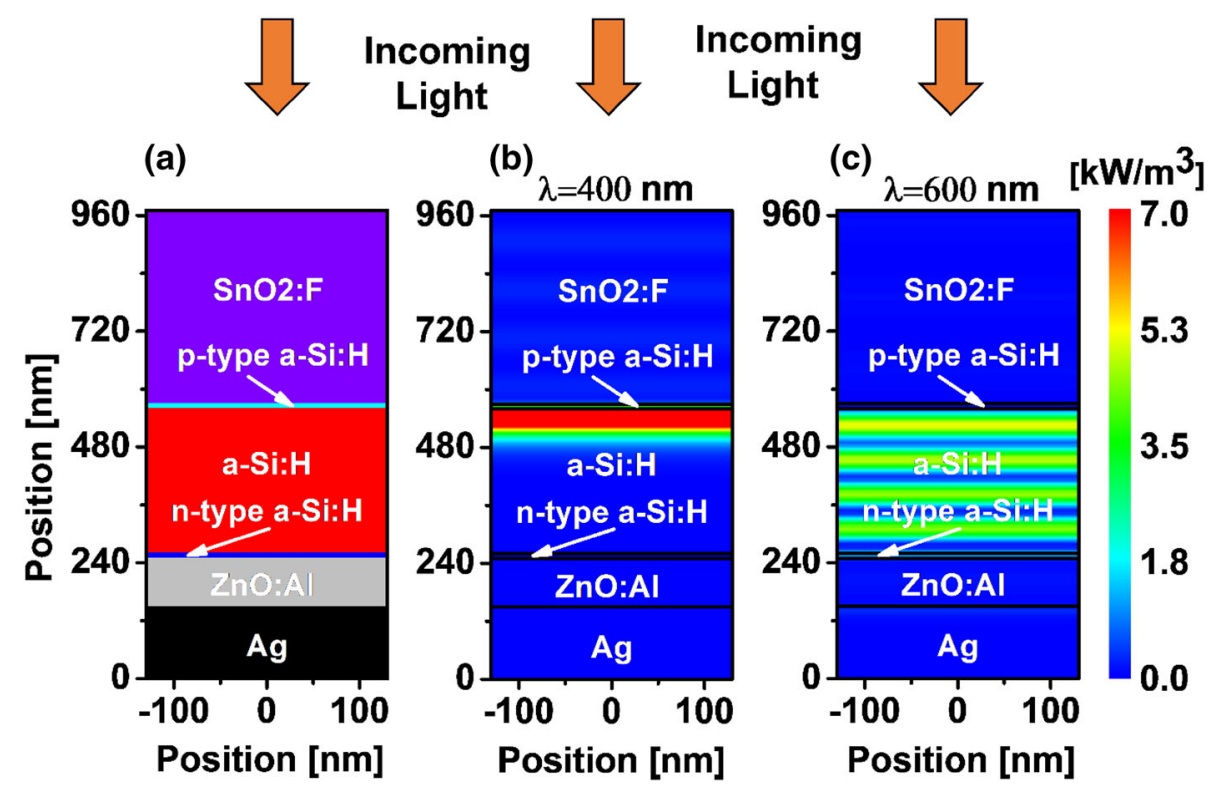

obstructions of the forward and in reverse spreading waves (Dewan et al. 2012; Palanchoke et al. 2012; Tamang et al. $2016 b)$. It is surveyed that the light with a shorter wavelength $(400 \mathrm{~nm})$ is retained inside a couple of many nanometers of the solar cell, since amorphous silicon displays a high absorption coefficient for shorter wavelengths, where light does not reach to the back reflector (Dewan et al. 2012; Tamang et al. 2016b, c).

Because of the low absorption coefficient of amorphous silicon for longer wavelengths, a huge part of the light is reflected from the back contact prompting the development of a standing wave before the terminal contact (Tamang et al. 2016b). For this situation, $45 \%$ of the incoming light was reflected, though the amorphous silicon layer absorbed just $49 \%$ of the light and rest of the light was considered as a parasitic loss. With expanding wavelength, photon absorption is diminished in the solar cell. Therefore, proficient light-trapping ideas are required to improve the effective thickness of the solar cell for longer wavelengths (Haug et al. 2009; Paetzold et al. 2011; Dewan et al. 2012). Besides, the a-Si:H cells for the various back contacts ( $\mathrm{ZnO}: \mathrm{Al} /$ air, $\mathrm{ZnO}: \mathrm{Al} / \mathrm{Al}$, and $\mathrm{ZnO}: \mathrm{Al} / \mathrm{PEC}$ ) were researched inside the same solar cell structure. To understand the solar cell execution of different back reflectors, the quantum efficiency was also studied which can be characterized utilizing the following equation (Jovanov et al. 2013a, b):

$\mathrm{QE}=\frac{1}{P_{\mathrm{Opt}}} \iiint Q(x, y, z) \mathrm{d} x \mathrm{~d} y \mathrm{~d} z$,

where $P_{\text {Opt }}$ is the incoming solar power on the unit cell. The impact of utilizing several back reflectors on optical absorption was examined by determining quantum efficiency.
A relative study of external quantum efficiency and reflection losses depicted in Fig. 4a, b was carried on the flat substrate. As it is seen from Fig. 4a, back reflector does not impact on photon absorption for the shorter wavelength $(<500 \mathrm{~nm})$. Whereas the majority of the QEs demonstrate comparable qualities, the most reduced photon retention was found for the $\mathrm{ZnO}$ :Al/air back contact because of their base reflection at the back. A noteworthy change in $\mathrm{QE}$ is observed for the $\mathrm{ZnO}: \mathrm{Al} / \mathrm{PEC}$ case, while the highest peak of $\mathrm{QE}$ is discovered (80\%) for the $\mathrm{ZnO}: \mathrm{Al} / \mathrm{Ag}$ at $575-\mathrm{nm}$ wavelength. A little change in QE can be seen for the 700$800-\mathrm{nm}$ wavelength because of the lower absorption coefficient of amorphous silicon and for the further increment in wavelength amorphous silicon shows nearly zero absorption. A noticeable change in $\mathrm{QE}$ is exhibited for the wavelength of 550-700 $\mathrm{nm}$. In addition, it is perceptible, as shown Fig. 4a, b, most extreme reflection from the back improves quantum productivity through the cell for the smooth substrate. The most surprising observation is right around $95 \%$ for the perfect electrical conductor case because of its excellent material properties. For the further examination, the short-circuit current density was resolved given simulated quantum proficiency. The short-circuit current was utilized using the following equation (Dewan et al. 2012, 2015b):

$I_{\mathrm{SC}}=\frac{q}{h c} \int \lambda \times \mathrm{QE}(\lambda) \times S(\lambda) \mathrm{d} \lambda$,

where $q$ is an initial charge, $\lambda$ is the wavelength, $h$ is the Planck steady, $c$ is the speed of light, and $S(\lambda)$ is the weighted spectral range (AM 1.5). The simulated impede alongside the reflection loss and parasitic losses at alternate layers of the solar cell are condensed in Table 1. 
Fig. 4 a Comparison of quantum efficiencies for solar cell with smooth air, $\mathrm{Al}, \mathrm{Ag}$, and PEC back reflectors and b their corresponding reflection losses (a)

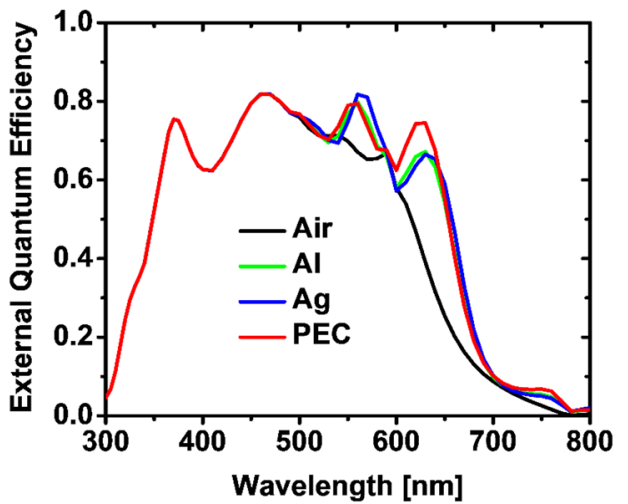

(b)

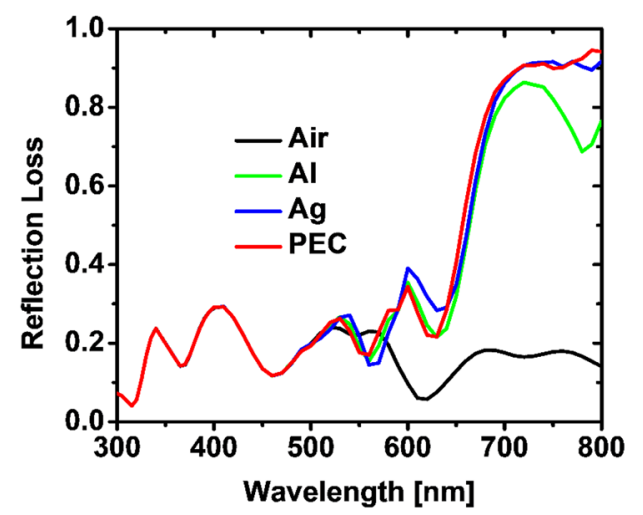

It is seen from Table 1; the short-circuit current density differs from 11.5 to $13.27 \mathrm{~mA} / \mathrm{cm}^{2}$, where the most extreme current is found for the $\mathrm{ZnO}: \mathrm{Al} / \mathrm{PEC}$ back contact because of the higher reflection from the back. It is additionally observed that higher short-circuit current density likewise shows a higher reflection loss. Enormous changes are realized in the absorption of terminal contact, which incorporates back transparent conductive oxide and metal reflector. Nonetheless, parasitic losses are reasonably the same for each case. After practical examinations, beyond any doubt, the reflection loss restrains the overall conversion efficiencies; in this way, the particular layer interface can upgrade the total short-circuit current density, quantum efficiency, and power conversion efficiency of a solar cell (Jovanov et al. 2013a, c). In addition, the state of the back reflector impacts photon absorption inside the solar cell.

\section{Solar cell with pyramid texture substrate}

In the accompanying power loss profile, quantum efficiency and short-circuit current were figured on pyramid textured substrate for the various back reflectors (Dewan et al. 2011; Tamang et al. 2016a; Jovanov et al. 2017). The thickness of the solar cell was kept consistent, so that a correlation amongst smooth and textured cases can be observed. The profundities of the period and heights of the interface surface were viewed as 260 and $75 \mathrm{~nm}$, individually. The comparing opening edge of the pyramid surface was kept constant to $120^{\circ}$. The cross segment of the pyramidal textured amorphous silicon solar cell is shown in Fig. 5a.

The power loss was figured utilizing Eq. (1), and power loss profiles using silver back reflector under blue $(\lambda=400 \mathrm{~nm})$ and red $(\lambda=700 \mathrm{~nm})$ enlightenments are shown in Fig. 5b, c, separately. For the shorter wavelength $(\lambda=400 \mathrm{~nm})$, photon gets absorbed inside a couple of hundred nanometers, and there is not much photon absorption found in the front TCO layer. No absorption is realized for alternate layers (Zeman et al. 2000; Dewan et al. 2011; Palanchoke et al. 2012). With expanding wavelength, the photons enter further in the amorphous silicon absorber. Because of the low absorption coefficient of amorphous silicon for longer wavelength $(\lambda=700 \mathrm{~nm})$, light needs to finish numerous path in the solar cell. The approaching light achieves the back contact of the sunbased cell, where it gets reflected and completed different paths inside the solar cell (Dewan et al. 2012; Jovanov et al. 2013c; Tamang et al. 2016b). From Fig. 5c, a, significant photon absorption is observed in the textured solar cell contrasted with a smooth substrate.

Table 1 Summary of short-circuit current density, reflection loss, and absorption losses regarding current density for the individual layers of the solar cell on the smooth substrate for the various back contacts

\begin{tabular}{|c|c|c|c|c|c|c|c|}
\hline \multirow{2}{*}{$\begin{array}{l}\text { Back contact } \\
\text { configuration }\end{array}$} & \multicolumn{6}{|c|}{ Optical absorption losses at the individual layers $\left(\mathrm{mA} / \mathrm{cm}^{2}\right)$} & \multirow{2}{*}{$\begin{array}{l}\text { Reflection loss (mA/ } \\
\left.\mathrm{cm}^{2}\right)\end{array}$} \\
\hline & $\begin{array}{l}\text { Short-circuit current density } \\
\text { a-Si:H }\end{array}$ & $\begin{array}{l}\mathrm{FTCO} \\
\mathrm{SnO}_{2}: \mathrm{F}\end{array}$ & $\begin{array}{l}\text { p-doped } \\
\text { a-Si:H }\end{array}$ & $\begin{array}{l}\text { n-doped } \\
\text { a-Si:H }\end{array}$ & $\begin{array}{l}\text { BTCO } \\
\mathrm{ZnO}: \mathrm{Al}\end{array}$ & Metal & \\
\hline $\mathrm{ZnO}: \mathrm{Al} / \mathrm{air}$ & 11.50 & 0.82 & 0.13 & 0.63 & 0.07 & 9.67 & 4.57 \\
\hline $\mathrm{ZnO}: \mathrm{Al} / \mathrm{Ag}$ & 13.17 & 0.92 & 0.13 & 0.17 & 0.22 & 0.11 & 12.10 \\
\hline $\mathrm{ZnO}: \mathrm{Al} / \mathrm{Al}$ & 12.99 & 0.91 & 0.13 & 0.18 & 0.83 & 0.68 & 11.10 \\
\hline $\mathrm{ZnO}: \mathrm{Al} / \mathrm{PEC}$ & 13.27 & 0.92 & 0.13 & 0.21 & 0.08 & 0.0 & 12.20 \\
\hline
\end{tabular}


Fig. 5 a Schematic of a pyramidal textured unit cell using Ag reflector and simulated power loss profiles with a period of $260 \mathrm{~nm}$ and a profile height of $75 \mathrm{~nm}$ under monochromatic illumination of wavelengths a 400 and b $700 \mathrm{~nm}$
Fig. 6 a Comparison of quantum efficiencies for the solar cell on a pyramidal textured air, $\mathrm{Al}, \mathrm{Ag}$, and $\mathrm{PEC}$ back reflectors and $\mathbf{b}$ their corresponding reflection losses

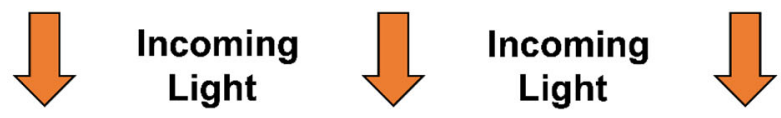

(a)

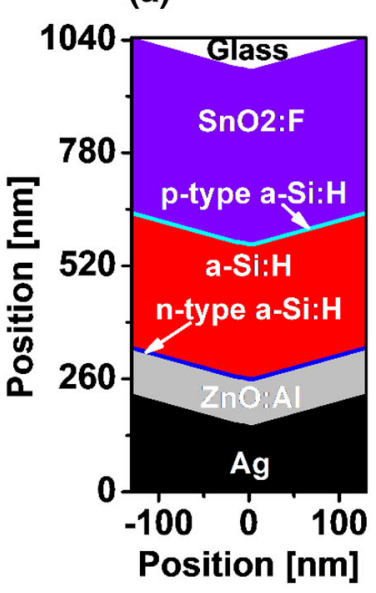

(b)

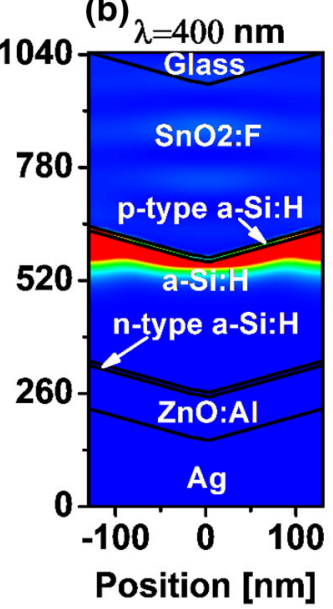

(c)

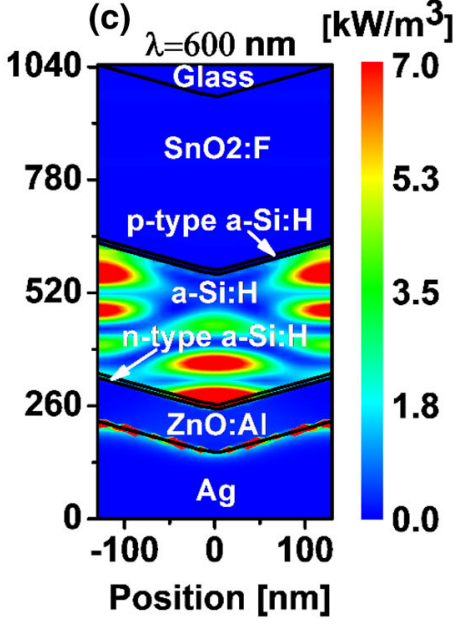

(a)

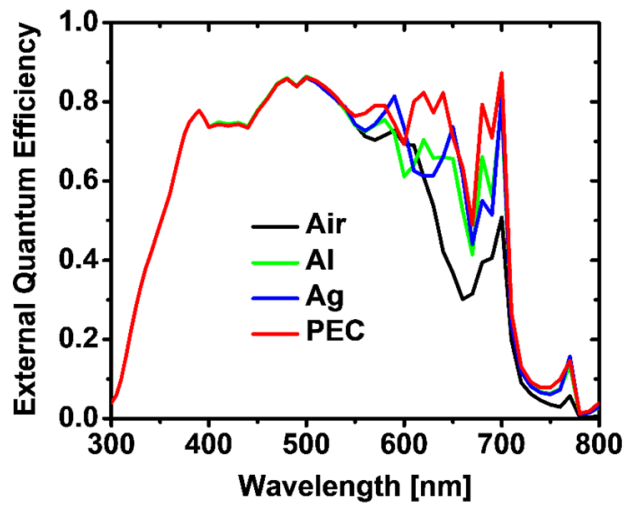

(b)

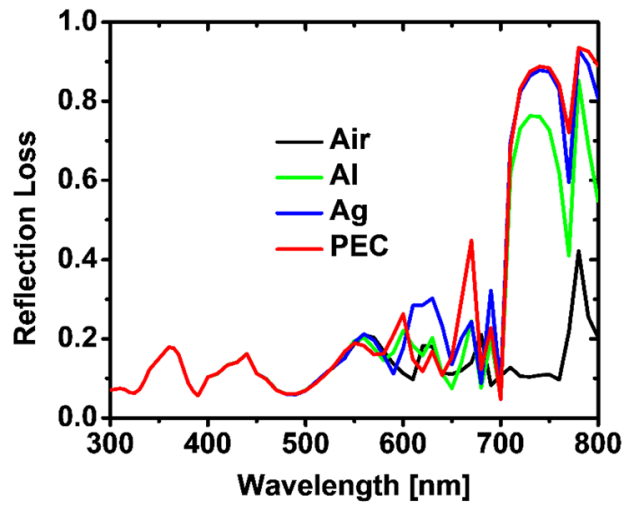

The opening edge of the pyramid is near $120^{\circ}$, so more light is conformed closer to the back reflector (Jovanov et al. 2013b; Dewan et al. 2015b; Tamang et al. 2016a). In addition, all the standing waves are visible within the diode which is noteworthy contrasted with the flat case. Moreover, external quantum efficiency and short-circuit current density were calculated utilizing Eqs. (2) and (3), respectively. An examination between the quantum efficiencies and reflection losses is described in Fig. 6a, b, separately.

An enhanced quantum efficiency is seen in the pyramidal textured case contrasted with a solar cell designed on the smooth substrate due to the improved light incoupling and diffusion adding up to reflection at the back (Springer et al. 2004; Jovanov et al. 2013b; Palanchoke et al. 2013). Contrastively, a huge change in QE is perceived for the pyramidal textured solar cell inside a shorter wavelength extent $(<500 \mathrm{~nm})$, where it was low in the cell on a smooth substrate. A reduction of reflection loss for the shorter wavelength is contracted, which likewise helps to enhance the external quantum proficiency and short-circuit current. A higher QE in the more extended wavelength is articulated in textured case, where the upper peak is found at the $700-\mathrm{nm}$ wavelength. The QE enhances up to $400 \mathrm{~nm}$ of wavelength. However, a little lessening in QE is pronounced between 400 and $450 \mathrm{~nm}$ before it rises to a crest point at 490-nm wavelength. Then, it starts to fall, and some high peaks are found between 550 and $780 \mathrm{~nm}$. After $800 \mathrm{~nm}$ of wavelength, however, there is no assimilation in the solar cell. Hence, a higher reflection loss is found in the $\mathrm{ZnO}: \mathrm{Al} / \mathrm{PEC}$ case and lower reflection loss is found for the $\mathrm{ZnO}: \mathrm{Al} / \mathrm{air}$ case. Moreover, the examination was accomplished by determining to short-circuit current density; right around 24\% higher short-circuit current is found in the textured case contrasted with the cell on a smooth substrate.

Because of the enhanced effective thickness, higher losses in the doped layers and contact layers were inspected, which are considered as parasitic losses and not 
Table 2 Summary of short-circuit current density, reflection loss, and absorption losses concerning current density of the individual layers of the pyramid textured using different back contact configurations

\begin{tabular}{|c|c|c|c|c|c|c|c|}
\hline \multirow{2}{*}{$\begin{array}{l}\text { Back contact } \\
\text { configuration }\end{array}$} & \multicolumn{6}{|c|}{ Optical absorption losses at the individual layers $\left(\mathrm{mA} / \mathrm{cm}^{2}\right)$} & \multirow{2}{*}{$\begin{array}{l}\text { Reflection loss (mA/ } \\
\left.\mathrm{cm}^{2}\right)\end{array}$} \\
\hline & $\begin{array}{l}\text { Short-circuit current density } \\
\text { a-Si:H }\end{array}$ & $\begin{array}{l}\mathrm{FTCO} \\
\mathrm{SnO}_{2}: \mathrm{F}\end{array}$ & $\begin{array}{l}\text { p-doped } \\
\text { a-Si:H }\end{array}$ & $\begin{array}{l}\text { n-doped } \\
\text { a-Si:H }\end{array}$ & $\begin{array}{l}\mathrm{BTCO} \\
\mathrm{ZnO}: \mathrm{Al}\end{array}$ & Metal & \\
\hline $\mathrm{ZnO}: \mathrm{Al} / \mathrm{air}$ & 13.81 & 0.93 & 0.44 & 0.22 & 0.13 & 7.5 & 3.78 \\
\hline $\mathrm{ZnO}: \mathrm{Al} / \mathrm{Ag}$ & 15.36 & 1.0 & 0.45 & 0.32 & 1.11 & 0.3 & 8.27 \\
\hline $\mathrm{ZnO}: \mathrm{Al} / \mathrm{Al}$ & 15.26 & 0.98 & 0.42 & 0.27 & 1.16 & 1.76 & 6.97 \\
\hline $\mathrm{ZnO}: \mathrm{Al} / \mathrm{PEC}$ & 16.36 & 1.0 & 0.46 & 0.36 & 0.31 & 0.02 & 8.31 \\
\hline
\end{tabular}

Fig. 7 Simulated external quantum efficiency, total absorption within the pyramidal textured cell, total reflection, parasitic absorption in $\mathrm{SnO}_{2}: \mathrm{F}$, p-doped a-Si:H, n-doped a-Si:H, $\mathrm{ZnO}: \mathrm{Al}$, and PEC with the terrestrial solar radiation spectrum of $1.5 \mathrm{G}$

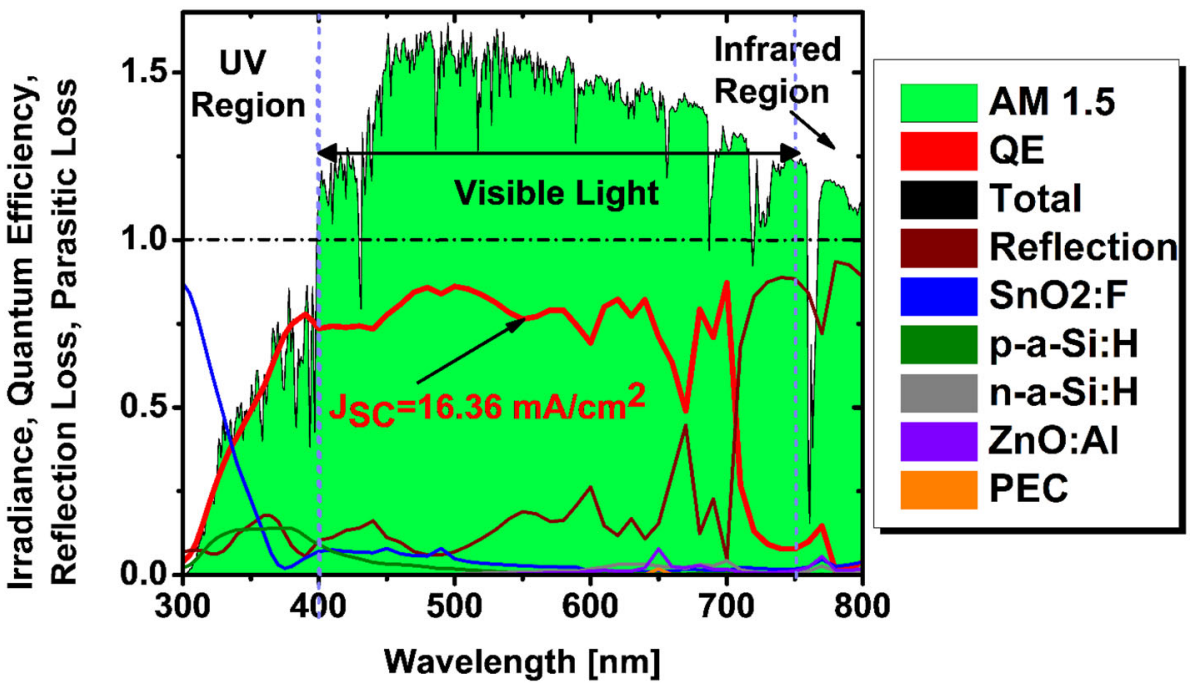

contributing to short-circuit current (Paetzold et al. 2011; Tan et al. 2013; Tamang et al. 2016b). The simulated cutoff alongside the reflection loss and parasitic losses at alternate layers of the solar cell saved on textured pyramid substrate is shown in Table 2 .

The table represents the comparison of short-circuit currents, where a maximum short-circuit current density value $\left(16.36 \mathrm{~mA} / \mathrm{cm}^{2}\right)$ is found for the PEC reflectors and minimum $\left(13.81 \mathrm{~mA} / \mathrm{cm}^{2}\right)$ for the case, where the air used as a reflector. The corresponding reflection losses for both the cases are almost similar which is significant compared to other reflectors. Doped layers and first transparent layer exhibit nearly constant absorption for all the cases. However, losses in the air compared to other reflectors have a significant value. Therefore, it seems that more investigations are needed to improve solar cell performance regarding QE, and parasitic losses within the solar cell structure.

A detail absorption range for each layer of the simulated textured amorphous solar cell with perfect electrical conductor reflector alongside the spectral irradiance of sunlight
(AM 1.5) is depicted in Fig. 7 for the wavelength scope of 300-800 nm (Sai and Kondo 2009a; Palanchoke et al. 2012; Jovanov et al. 2013a). The black dotted line demonstrates the total sum of photon absorbed by the unit cell over the entire wavelength range, which is considered as $100 \%$ for the reproduction. From the external quantum efficiency range (red curve) of the simulated solar cells, it is understood that the cell crests at just about $85 \%$ in the wavelength between 510 and $710 \mathrm{~nm}$. A relative decline in the outside quantum productivity of the solar cell, be that as it may, is expressed in the blue piece of the unique light range $(400-450 \mathrm{~nm})$. It is likewise seen from the power loss profile explained in Figs. $3 \mathrm{~b}$ and $5 \mathrm{~b}$ that there is an immense power loss in that locale and it does not add to the yield influence (Trapping et al. 2011; Dewan et al. 2011, 2015b). In general, the active layer and parasitic losses are shown in Fig. 7, the $\mathrm{SnO}_{2}: \mathrm{F}$, a-Si:H, p-doped a-Si:H, n-doped a-Si:H, ZnO:Al, and PEC metal layers absorb $3.72,61,1.72,1.34,1.2$, and $\approx 0.0 \%$ photons, separately, of the total absorption inside solar cell. As it is specified before, the quantum proficiency was limited 
because of the higher reflection loss; if these higher losses are limited, the collective QE consequently hamper thickness will be additionally progressed. It is seen from Fig. 7 that indistinct silicon absorbs a remarkable number of photons in the distinctive range contrasted with UV and infrared range, which can be additionally upgraded by presenting certain interface building.

\section{Conclusion}

The impact of rear reflectors on light trapping and photon management in amorphous silicon solar cells with smooth and pyramidal surfaces has been effectively explored. Figured power loss profiles from the 3D optical simulation have appeared for the absorption in the various regions inside the solar cell structure. To enhance the light trapping within the solar cell, an improved design structure has proposed, where a pyramidal surface utilized at the interfaces of the solar cell structure. The pyramidal surface diminishes the general reflection losses and upgrades the photon dissipating/ diffraction in the cell. A maximum short-circuit current for the smooth and textured substrates has been accomplished 13.27 and $16.36 \mathrm{~mA} / \mathrm{cm}^{2}$, separately. Contrasted with the flat structure, the textured solar cell displays just about $24 \%$ higher short-circuit current density. Simulated parasitic losses were researched for every one of the layers which were not added to the short-circuit density. This upgraded cell can be additionally investigated to improve the general photon absorption, and also, control changes productivity.

Acknowledgements The authors want to express gratitude toward Prof. Dr. Dietmar Knipp, Dr. Rahul Dewan, and Dr. Vladislav Jovanov (Jacobs University Bremen) for educating the plan of FDTD calculation. This work is partly financially supported by The Hong Kong Polytechnic University (Grant code: G-YBFR, G-UA7N).

\section{Compliance with ethical standards}

Conflict of interest The author(s) declare(s) no conflict of interest regarding the publication of this paper.

Open Access This article is distributed under the terms of the Creative Commons Attribution 4.0 International License (http:// creativecommons.org/licenses/by/4.0/), which permits unrestricted use, distribution, and reproduction in any medium, provided you give appropriate credit to the original author(s) and the source, provide a link to the Creative Commons license, and indicate if changes were made.

\section{References}

Barugkin C, Paetzold UW, Catchpole KR et al (2016) Highly reflective dielectric back reflector for improved efficiency of tandem thin-film solar cells. Int J Photoenergy 2016:1-7. doi:10. $1155 / 2016 / 7390974$
Catchpole KR, Polman A (2008) Plasmonic solar cells. Opt Express 16:21793. doi:10.1364/OE.16.021793

Chen A, Yuan Q, Zhu K (2016) ZnO/a-Si distributed Bragg reflectors for light trapping in thin film solar cells from visible to infrared range. Appl Surf Sci 360:1-12. doi:10.1016/j.apsusc.2015.11. 047

Dewan R, Knipp D (2009) Light trapping in thin-film silicon solar cells with integrated diffraction grating. J Appl Phys. doi:10. $1063 / 1.3232236$

Dewan R, Vasilev I, Jovanov V, Knipp D (2011) Optical enhancement and losses of pyramid textured thin-film silicon solar cells. J Appl Phys 110:13101. doi:10.1063/1.3602092

Dewan R, Owen JI, Madzharov D et al (2012) Analyzing nanotextured transparent conductive oxides for efficient light trapping in silicon thin film solar cells. Appl Phys Lett 101:103903-103904

Dewan R, Jovanov V, Hamraz S, Knipp D (2015a) Analyzing periodic and random textured silicon thin film solar cells by Rigorous Coupled Wave Analysis. Sci Rep 4:6029. doi:10.1038/ srep06029

Dewan R, Shrestha S, Jovanov V et al (2015b) Random versus periodic: determining light trapping of randomly textured thin film solar cells by the superposition of periodic surface textures. Sol Energy Mater Sol Cells 143:183-189. doi:10.1016/j.solmat. 2015.06.014

Dubey RS, Saravanan S, Kalainathan S (2014) Performance enhancement of thin film silicon solar cells based on distributed Bragg reflector \& diffraction grating. AIP Adv 4:127121. doi:10.1063/ 1.4904218

Escarre J, Soderstrom K, Battaglia C et al (2011) High fidelity transfer of nanometric random textures by UV embossing for thin film solar cells applications. Sol Energy Mater Sol Cells 95:881-886. doi:10.1016/j.solmat.2010.11.010

Ferry VE, Verschuuren MA, Li HBT et al (2009) Improved redresponse in thin film a-Si:H solar cells with soft-imprinted plasmonic back reflectors. Appl Phys Lett 95:183503. doi:10. $1063 / 1.3256187$

Ferry VE, Verschuuren MA, Li HBT et al (2010) Light trapping in ultrathin plasmonic solar cells. Opt Express 18:A237. doi:10. 1364/OE.18.00A237

Green MA (2006) Third generation photovoltaics, vol 12. Springer, Berlin, Heidelberg. doi:10.1007/b137807

Haug F-J, Soderstrom T, Domine D, Ballif C (2009) Light trapping effects in thin film silicon solar cells. MRS Proc 1153:1153-A131. doi:10.1557/PROC-1153-A13-01

Hsu C, Burkhard GF, McGehee MD, Cui Y (2011) Effects of nanostructured back reflectors on the external quantum efficiency in thin film solar cells. Nano Res 4:153-158. doi:10.1007/ s12274-010-0064-y

Huang H, Lu L, Wang J et al (2013) Performance enhancement of thin-film amorphous silicon solar cells with low cost nanodent plasmonic substrates. Energy Environ Sci 6:2965. doi:10.1039/ c3ee41139g

Jovanov V, Palanchoke U, Magnus P et al (2013a) Light trapping in periodically textured amorphous silicon thin film solar cells using realistic interface morphologies. Opt Express 21:A595A606. doi:10.1364/Oe.21.00a595

Jovanov V, Xu X, Shrestha S et al (2013b) Influence of interface morphologies on amorphous silicon thin film solar cells prepared on randomly textured substrates. Sol Energy Mater Sol Cells 112:182-189. doi:10.1016/j.solmat.2013.01.017

Jovanov V, Xu X, Shrestha S et al (2013c) Predicting the interface morphologies of silicon films on arbitrary substrates: application in solar cells. ACS Appl Mater Interfaces 5:7109-7116. doi:10. 1021/am401434y

Jovanov V, Moulin E, Haug F-J et al (2017) From randomly selftextured substrates to highly efficient thin film solar cells: 
influence of geometric interface engineering on light trapping, plasmonic losses and charge extraction. Sol Energy Mater Sol Cells 160:141-148. doi:10.1016/j.solmat.2016.10.005

Kim SH, Lee HC, Kim WY et al (2011) Performance improvement of microcrystalline thin film silicon solar cells by back reflector with high resistivity and low absorption. In: 2011 37th IEEE photovoltaic specialists conference. IEEE, pp 000638-000640

Konagai M (2011) Present status and future prospects of silicon thinfilm solar cells. Jpn J Appl Phys 50:030001. doi:10.1143/JJAP. 50.030001

Muller J, Kluth O, Wieder S et al (2001) Development of highly efficient thin film silicon solar cells on texture-etched zinc oxidecoated glass substrates. Sol Energy Mater Sol Cells 66:275-281. doi:10.1016/S0927-0248(00)00184-7

Muller J, Rech B, Springer J, Vanecek M (2004) TCO and light trapping in silicon thin film solar cells. Sol Energy 77:917-930. doi:10.1016/j.solener.2004.03.015

Paetzold UW, Moulin E, Pieters BE et al (2011) Design of nanostructured plasmonic back contacts for thin-film silicon solar cells. Opt Express 19:A1219. doi:10.1364/OE.19.0A1219

Palanchoke U, Jovanov V, Kurz H et al (2012) Plasmonic effects in amorphous silicon thin film solar cells with metal back contacts. Opt Express 20:6340-6347. doi:10.1364/OE.20.006340

Palanchoke U, Jovanov V, Kurz H et al (2013) Influence of back contact roughness on light trapping and plasmonic losses of randomly textured amorphous silicon thin film solar cells. Appl Phys Lett. doi:10.1063/1.4793415

Sai H, Kondo M (2009a) Effect of self-orderly textured back reflectors on light trapping in thin-film microcrystalline silicon solar cells. J Appl Phys 105:94511. doi:10.1063/1.3108689

Sai H, Kondo M (2009b) Effect of self-orderly textured back reflectors on light trapping in thin-film microcrystalline silicon solar cells. J Appl Phys. doi:10.1063/1.3108689
Springer J, Poruba A, Müllerova L et al (2004) Absorption loss at nanorough silver back reflector of thin-film silicon solar cells. J Appl Phys 95:1427-1429. doi:10.1063/1.1633652

Tamang A, Hongsingthong A, Jovanov V et al (2016a) Enhanced photon management in silicon thin film solar cells with different front and back interface texture. Sci Rep 6:29639. doi:10.1038/ srep29639

Tamang A, Hongsingthong A, Sichanugrist P et al (2016b) On the potential of light trapping in multiscale textured thin film solar cells. Sol Energy Mater Sol Cells 144:300-308. doi:10.1016/j. solmat.2015.09.008

Tamang A, Sai H, Jovanov V et al (2016c) On the interplay of interface morphology and microstructure of high-efficiency microcrystalline silicon solar cells. Sol Energy Mater Sol Cells 151:81-88. doi:10.1016/j.solmat.2016.02.018

Tan H, Sivec L, Yan B et al (2013) Improved light trapping in microcrystalline silicon solar cells by plasmonic back reflector with broad angular scattering and low parasitic absorption. Appl Phys Lett. doi:10.1063/1.4802451

Trapping ML, Cells NS, Ferry VE et al (2011) Modeling light trapping in nanostructured solar cells. ACS Nano 5:10055-10064. doi:10.1021/nn203906t

Wang PH, Theuring M, Vehse $\mathrm{M}$ et al (2017) Light trapping in a-Si:H thin film solar cells using silver nanostructures. AIP Adv. doi:10. $1063 / 1.4973987$

Zeman M, Van Swaaij RACMM, Metselaar JW, Schropp REI (2000) Optical modeling of a-Si:H solar cells with rough interfaces: effect of back contact and interface roughness. J Appl Phys 88(11-13):6436-6443. doi:10.1063/1.1324690 